Article

\title{
Low-Power Laser Graphitization of High Pressure-High Temperature Nanodiamond Films
}

\author{
Konstantin G. Mikheev ${ }^{1, * \mathbb{D}}$, Tatyana N. Mogileva ${ }^{1}$, Arseniy E. Fateev ${ }^{1}$, Nicholas A. Nunn ${ }^{2,3}$, \\ Olga A. Shenderova ${ }^{2}$ and Gennady M. Mikheev ${ }^{1, *(D)}$ \\ 1 Institute of Mechanics, Udmurt Federal Research Center, UB RAS, Izhevsk 426067, Russia; \\ mogileva@udman.ru (T.N.M.); a.e.fateev@mail.ru (A.E.F.) \\ 2 Adamas Nanotechnologies, Inc., Raleigh, NC 27617, USA; nnunn@adamasnano.com (N.A.N.); \\ oshenderova@adamasnano.com (O.A.S.) \\ 3 Department of Chemistry, North Carolina State University, Raleigh, NC 27695, USA \\ * Correspondence: k.mikheev@udman.ru (K.G.M.); mikheev@udman.ru (G.M.M.); \\ Tel.: +7-3412-21-8955 (G.M.M.)
}

Received: 17 April 2020; Accepted: 7 May 2020; Published: 11 May 2020

\begin{abstract}
Laser-induced graphitization of $100 \mathrm{~nm}$ monocrystals of diamond particles synthesized by high-pressure high-temperature (HP-HT) methods is not typically observed. The current study demonstrates the graphitization of $150 \mathrm{~nm}$ HP-HT nanodiamond particles in ca. 20- $\mu \mathrm{m}$-thick thin films formed on a glass substrate when the intensity of a focused $633 \mathrm{~nm}$ He-Ne laser exceeds a threshold of $\sim 33 \mathrm{~kW} / \mathrm{cm}^{2}$. Graphitization is accompanied by green luminescence. The structure and morphology of the samples were investigated before and after laser excitation while using X-ray diffraction (XRD), Raman spectroscopy, atomic force (AFM), and scanning electron microscopy (SEM). These observations are explained by photoionization of [Ni-N]- and [N]-centers, leading to the excitation of electrons to the conduction band of the HP-HT nanodiamond films and an increase of the local temperature of the sample, causing the transformation of $\mathrm{sp}^{3} \mathrm{HP}-\mathrm{HT}$ nanodiamonds to $\mathrm{sp}^{2}$-carbon.
\end{abstract}

Keywords: nanodiamond; graphitization; laser; up-conversion luminescence

\section{Introduction}

A number of unique properties of nanodiamonds make them attractive for a variety of industrial and biomedical applications [1-4]. The mass production of nanodiamond particles is currently carried out by two methods: (i) detonation of high explosives with high carbon content [5,6] and (ii) milling micrometer-sized diamond particles [7] produced while using hydraulic presses at high pressure and high temperature [8]. Detonation nanodiamonds and high-pressure high-temperature (HP-HT) nanodiamonds both have a wide variety of impurities [5,9-11]. More than 60 elements are known to be present in diamonds according to analytical data, but only a few of them, namely nitrogen, boron, nickel, silicon, and hydrogen, can form intrinsic structural defects [12]. These impurities and vacancies affect the optical properties of nanodiamonds, such as absorption and luminescence.

HP-HT nanodiamonds contain substitutional nitrogen impurities with a concentration of about 100-300 ppm [11,13]. These substitutional nitrogen impurity atoms form stable complexes with vacancies (or other impurity atoms), leading to the formation of optically active defect centers. Among these are the well-studied nitrogen-vacancy $[\mathrm{N}-\mathrm{V}]$ (having both neutral $[\mathrm{N}-\mathrm{V}]^{0}$ and negatively charged $[\mathrm{N}-\mathrm{V}]^{-}$forms), consisting of one nitrogen atom $[\mathrm{N}]$ in a substitutional position and one vacancy [V] [14]. These complexes have a high probability of electronic transitions [15]. HP-HT nanodiamonds grown while using nickel or a nickel alloy as a catalyst contain a number of nickel related optical 
centers $[16,17]$. The absorption and luminescence spectra of the HP-HT nanodiamonds grown in the Fe-Ni-C system exhibit a large number of absorption lines in a wide spectral region (300-900 nm) belonging to [Ni]- $[16,18]$ and $[\mathrm{Ni}-\mathrm{N}]-[19,20]$ centers. The defect centers listed above, as well as other impurity centers formed during the synthesis of HP-HT nanodiamonds, can affect the material response to laser irradiation.

It is known that focused laser radiation can initiate processes that lead to laser modification of nanodiamonds. A large number of studies have demonstrated laser modification of the surface of single and polycrystalline diamonds, nanocrystalline diamond films, ultra-thin diamond-like carbon, amorphous diamond-like films, and tetrahedral amorphous carbon while using powerful nanosecond, picosecond, and femtosecond lasers operating in the ultraviolet, visible, and infrared ranges [21-28]. In these studies, laser microstructuring occurs as a result of local graphitization of the surface due to single- or multi-photon absorption (depending on the laser quantum energy) of powerful laser radiation, which causes the ionization of the $\mathrm{sp}^{3}$-carbon material.

Recently, we have demonstrated the possibility of blackening and microstructuring of semitransparent detonation nanodiamond films upon low-power focused He-Ne laser irradiation at $633 \mathrm{~nm}$ [29]. Such modification of the nanodiamond films can be used in order to fabricate optical structures designed on a micro-scale. Briefly, we have also demonstrated that cw He-Ne laser at a wavelength of $633 \mathrm{~nm}$ causes the transformation of HP-HT nanodiamonds into $\mathrm{sp}^{2}$-carbon (blackening) [30]. In the current paper, we have studied this phenomenon accompanied by green luminescence in more detail, which allows for us to establish a link between film blackening and the local presence of Ni-related photoluminescent centers.

\section{Materials and Methods}

The HP-HT nanodiamond particles with an average size of $150 \mathrm{~nm}$ were sourced from the vendor (Diamond Innovations, Worthington, OH, USA) and then dispersed in deionized water [30]. $20-\mu \mathrm{m}$-thick (see Figure $1 \mathrm{a}$ ) and $0.5 \mu \mathrm{m}$-thick films were obtained by dropping the HP-HT nanodiamond aqueous suspension on a quartz substrate and then drying it at room temperature. The $0.5-\mu \mathrm{m}$-thick films were used to study the extinction spectrum. The main experiments on laser modification were carried out with the 20- $\mu$ m-thick films. X-ray diffraction (XRD), Raman spectroscopy, atomic force microscopy (AFM), and scanning electron microscopy (SEM) were used to characterize the films and HP-HT nanodiamonds under study. HP-HT nanodiamond films are insulating; therefore, to eliminate the effect of charge accumulation on the surface in the course of examination with a scanning electron microscope, the surfaces of the films were sputtered with a thin layer of gold with a thickness of about $20 \mathrm{~nm}$.

A D2 PHASER diffractometer from Bruker was used to study the XRD patterns of nanodiamonds. A copper-based X-ray tube that generates radiation at wavelengths $\lambda_{1}(K \alpha 1$ line $)=0.1541 \mathrm{~nm}$, $\lambda_{2}(\mathrm{~K} \alpha 2$ line $)=0.1544 \mathrm{~nm}$, and $\lambda_{3}(\mathrm{~K} \beta$ line $)=0.1392 \mathrm{~nm}$ is used in the diffractometer. For the spectral separation of the $\mathrm{K} \alpha$ line, an $\mathrm{X}$-ray filter from a nickel plate that attenuates radiation at a wavelength of $\lambda_{3}$ is used. The $K \alpha 1$ and $K \alpha 2$ emission lines are a doublet; therefore, their spectral separation from each other using a nickel filter is not possible. However, the intensity of the $K \alpha 2$ spectral line is approximately two times lower than the intensity of the $K \alpha 1$ line. Thus, the diffraction lines of $K \alpha 1$ copper radiation should be noticeable in the X-ray diffraction pattern of the material under study.

The HP-HT nanodiamond powder obtained from the suspension was placed on a glass substrate to record XRD patterns. The XRD pattern of the substrate without powder was recorded separately. Then, to obtain a true diffraction pattern of the powder, the corresponding subtraction of the data of two experiments was carried out.

Figure 2 shows the diffraction pattern of the HP-HT nanodiamonds. One can see that, in the range of the angle $2 \theta$ from 25 to $100^{\circ}$, the pattern contains three large peaks and one small peak. Large peaks at $2 \theta$ angles of $43.9,75.3$ and $91.5^{\circ}$ correspond to $X$-ray diffraction $K \alpha$ on the $\{111\},\{220\}$, $\{311\}$ planes of diamond crystallites with interplanar distances $d_{111}=0.2060 \mathrm{~nm}, d_{220}=0.1261 \mathrm{~nm}$, and 
$d_{311}=0.1075 \mathrm{~nm}$, respectively, where the subscripts denote the crystallographic plane, according to the Powder Diffraction File (PDF) 00-006-0675 (see Figure 2 lower part). The weak peak at an angle of $2 \theta=39.5^{\circ}$ is due to the diffraction of the weak $\mathrm{CuK} \beta$ radiation line on the $\{111\}$ planes. Thus, $\mathrm{X}$-ray diffraction confirms that the sample under study is a high-quality diamond material.
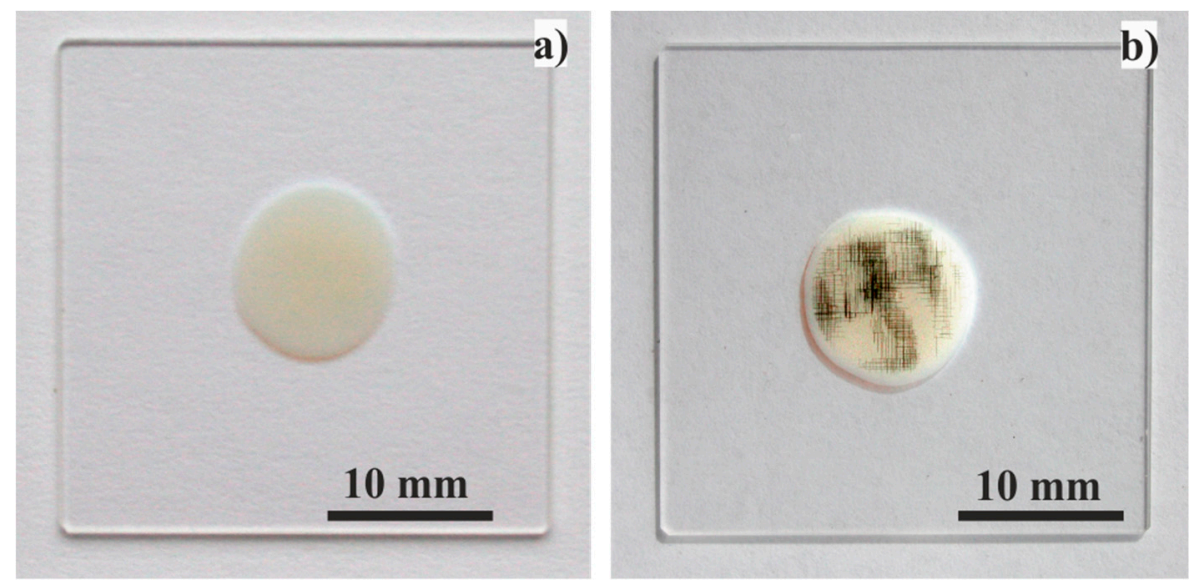

Figure 1. (a) Image of high-pressure high-temperature (HP-HT) nanodiamond film with a thickness of $20 \mu \mathrm{m}$ on a quartz substrate before laser irradiation; (b) image of $20-\mu \mathrm{m}$-thick HP-HT nanodiamond film with a thickness of $20 \mu \mathrm{m}$ on a quartz substrate after laser irradiation where a laser beam scanned the entire area of the film. Note that a portion of the film remained non-blackened

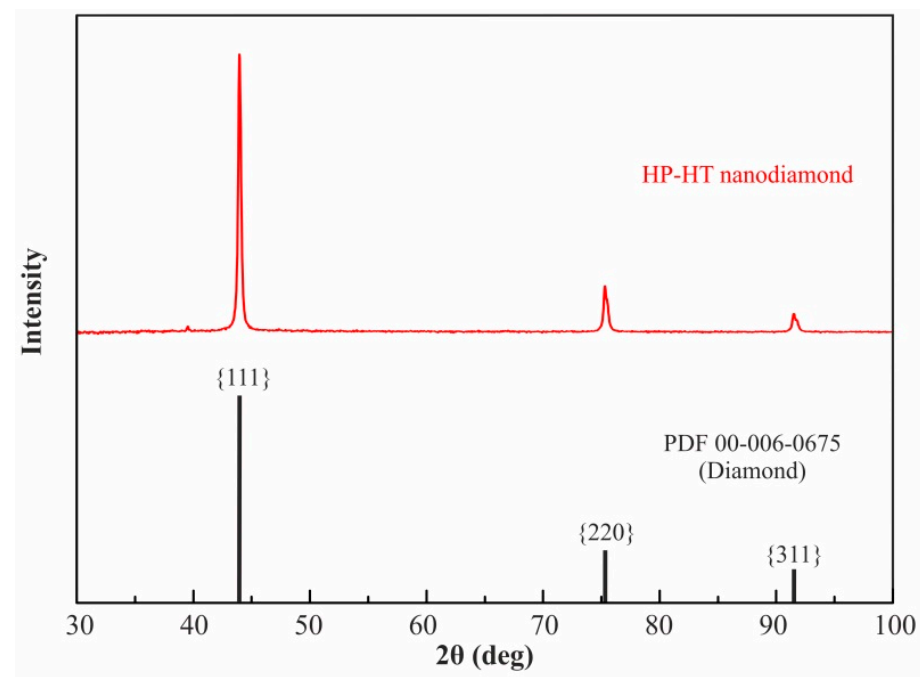

Figure 2. X-ray diffraction pattern of HP-HT nanodiamond powder and X-ray diffraction pattern of diamond (Powder Diffraction File 00-006-0675).

Figure 3a presents the scanning electron microscope Inspect S50 image of the film under study. Figure $3 b$ illustrates the typical morphology of the same film, measured with an atomic force microscope SOLVER 47 PRO. The images show that the film surface has a granular structure, with a characteristic size of the observed particles of about $150 \mathrm{~nm}$.

The extinction spectrum of the HP-HT nanodiamond film with a thickness of $0.5 \mu \mathrm{m}$ shows the maximum at the wavelength of $208 \mathrm{~nm}$, corresponding to the photon energy of $5.96 \mathrm{eV}$ (Figure 4a). This absorption band corresponds to the transition from the valence band to the conduction band of a diamond. Figure $4 \mathrm{a}$ also shows monotonically decreasing extinction of the film due to decreasing Rayleigh scattering by nanoparticles and film inhomogeneities with the increase in the wavelength. 
a)

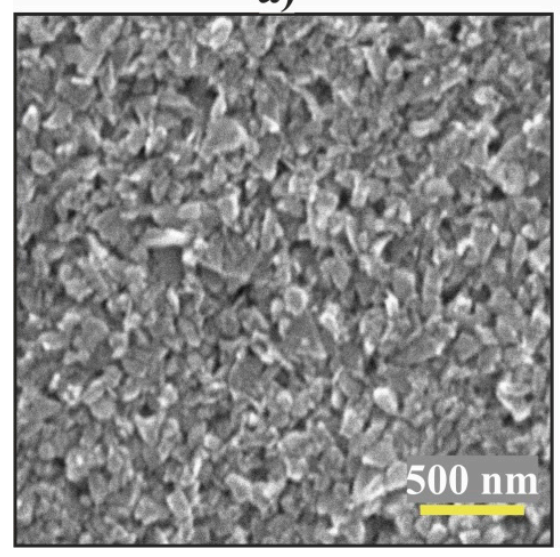

b)

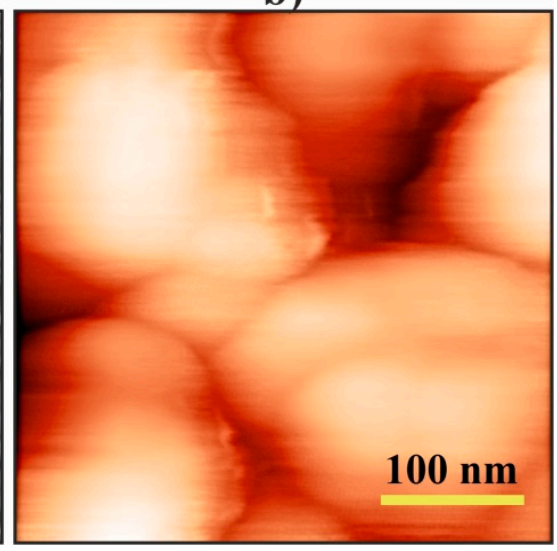

Figure 3. Scanning electron microscopy (SEM (a) and atomic force microscopy (AFM) (b) images of the HP-HT nanodiamond film surface.

a)

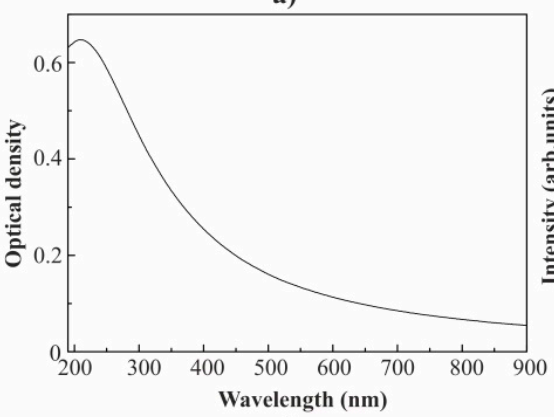

c)

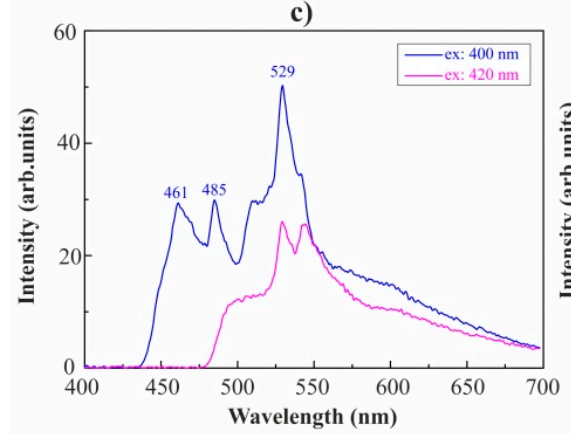

b)

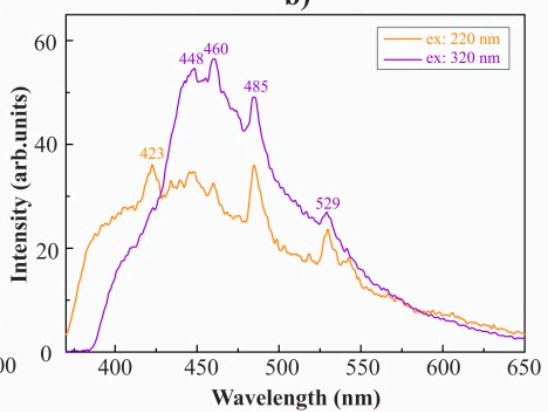

d)

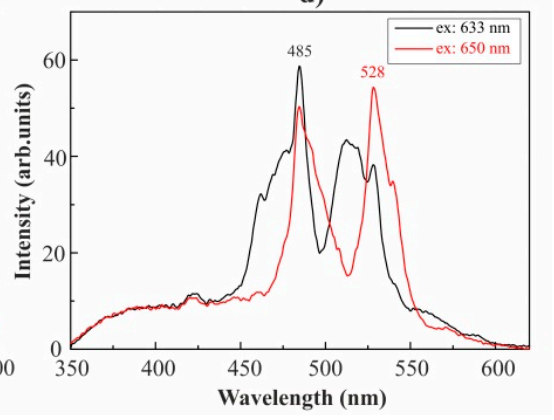

Figure 4. (a) Extinction spectrum of the HP-HT nanodiamond film with a thickness of $0.5 \mu \mathrm{m}$; (b) the luminescence spectra of the aqueous HP-HT nanodiamond suspension with concentration of $0.02 \mathrm{wt} . \%$ when excited by radiation at wavelengths of (b) 220 and $320 \mathrm{~nm}$, (c) 400 and $420 \mathrm{~nm}$; and, (d) the up-conversion luminescence spectra of aqueous HP-HT nanodiamond suspension with a concentration of $0.02 \mathrm{wt} \%$ when excited by radiation at wavelengths of 633 and $650 \mathrm{~nm}$.

The luminescence spectra of an aqueous suspension of HP-HT nanodiamonds were studied while using the LS55 luminescence spectrophotometer (Perkin Elmer). It allows for changing the wavelength of the exciting radiation using the excitation monochromator in the range from 200 to $800 \mathrm{~nm}$. The spectral range of the emission monochromator spans from 200 to $900 \mathrm{~nm}$. The luminescence intensity of the suspension was recorded, depending on the wavelength of the exciting radiation using a photomultiplier installed at the output of the emission monochromator. When recording the luminescence spectra, the slit widths of both monochromators were equal and set to $5 \mathrm{~nm}$. At the input of the emission monochromator, various optical filters significantly suppressing the exciting radiation were installed in order to reduce its influence on the luminescence spectra. 
Figure $4 b, c$ illustrate the luminescence spectra recorded in the Stokes region at excitation radiation wavelengths $\lambda_{\mathrm{ex}}=220,320,400$, and $420 \mathrm{~nm}$. It can be seen that when the wavelength $\lambda_{\mathrm{ex}}$ is changed, the luminescence spectrum changes too. However, in all recorded spectra, there are peaks that are common to all excitation wavelengths $\lambda_{\text {ex }}$. These are the peaks that correspond to the wavelengths of 461,485 , and $529 \mathrm{~nm}$.

Figure $4 \mathrm{~d}$ shows the luminescence spectra recorded in the anti-Stokes region when excited by radiation at wavelengths $\lambda_{\mathrm{ex}}=633$ and $650 \mathrm{~nm}$. This spectrum clearly shows up-conversion luminescence bands in the blue $(461-490 \mathrm{~nm})$ and green $(510-535 \mathrm{~nm})$ wavelength regions. It is noteworthy that, in the blue and green regions of the optical spectrum, there are peaks at 485 and $528 \mathrm{~nm}$, respectively, which were observed when luminescence was excited by radiation at $\lambda_{\mathrm{ex}}=$ 220,300 , and $360 \mathrm{~nm}$. Note that all of the spectra in Figure $4 \mathrm{~b}-\mathrm{d}$ are identical to that of the HP-HT nanodiamond film presented in Figure 1a.

Experiments on the laser modification of HP-HT nanodiamond films and the study of their Raman spectra were carried out at the wavelength of $633 \mathrm{~nm}$ while using Horiba HR800 Raman spectrometer with a He-Ne excitation source. In this case, the laser radiation could be focused on the surface of the film using interchangeable objectives with a magnification of $10(10 \times), 50(50 \times)$, or $100(100 \times)$. The laser beam diameters (at a level of $1 / \mathrm{e}^{2}$ ) in the focal plane of the objectives were measured by scanning laser beam profilometer BC 106-VIS (ThorLabs) along the laser beam axis [31]. The diameters of the waist of a laser beam focused with $10 \times, 50 \times$, and $100 \times$ objectives were $20.7,7.4$, and $4.1 \mu \mathrm{m}$, respectively. The measurements carried out with a calibrated photodetector showed that the maximum laser power at a $100 \times$ objective output is $8.4 \mathrm{~mW}$. Thus, the maximum light intensity did not exceed $65 \mathrm{~kW} / \mathrm{cm}^{2}$. The Raman spectra of the films under study were measured at the intensity of $5.4 \mathrm{~kW} / \mathrm{cm}^{2}$.

In the experiments on laser modification, the HP-HT nanodiamond film with a thickness of $20 \mu \mathrm{m}$ on a quartz substrate was moving relative to the laser beam waist while using the coordinate table (see Figure 5a). One can see the photo of the HP-HT nanodiamond film that was irradiated step-by-step over the entire surface area presented in Figure $1 \mathrm{~b}$. The emission from the film during laser treatment was recorded while using a photo camera (see Figure $5 \mathrm{~d}$ ) after passing through a glass filter. The color glass filter was used to weaken the radiation at $633 \mathrm{~nm}$, reflected from the film. Figure $5 \mathrm{~b}$ shows the transmission spectrum of this glass filter.
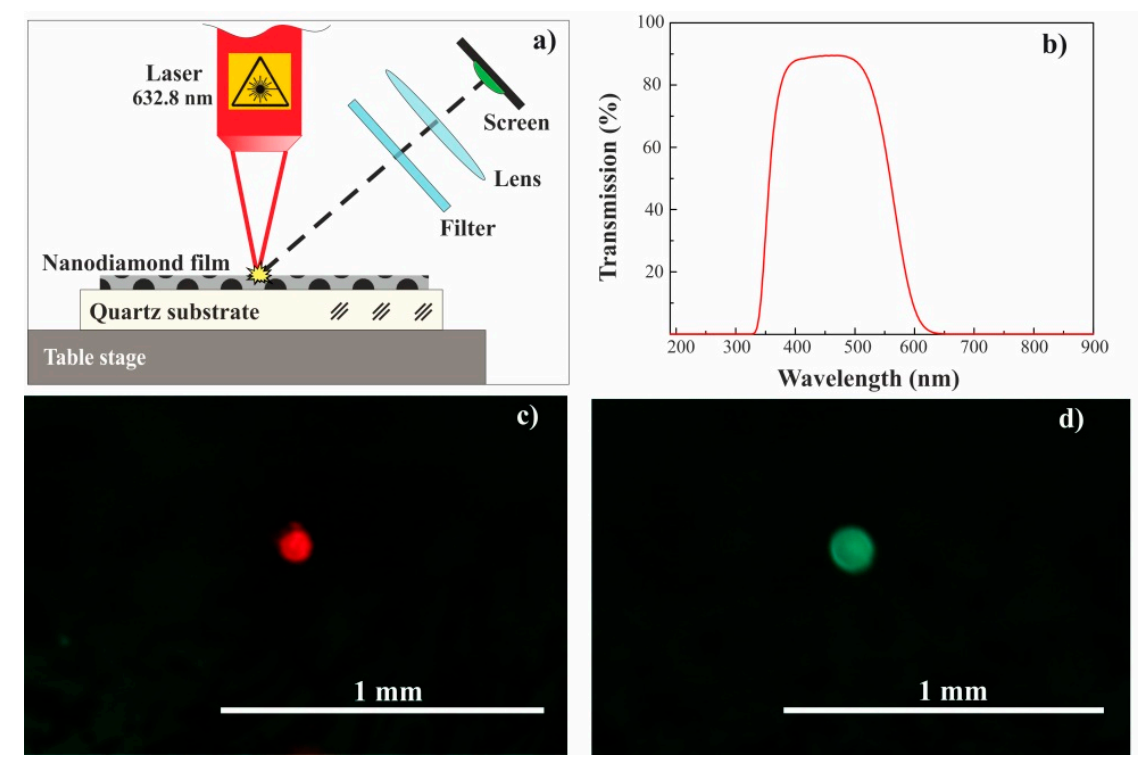

Figure 5. (a) A diagram of the experiment; (b) a transmission spectrum of the glass filter used to get images of the laser exposure area; the images of the laser beam spot at (c) $5.4 \mathrm{~kW} / \mathrm{cm}^{2}$ (no emission, only reflected red light) and (d) $65 \mathrm{~kW} / \mathrm{cm}^{2}$ (green emission is present). 


\section{Results}

It was found that at the threshold laser intensity of $33 \mathrm{~kW} / \mathrm{cm}^{2}$ the HP-HT nanodiamond film surface can start blackening in the laser beam waist area both in ambient and Ar atmospheres. When the film and the focused beam move relative to each other at a low speed (about $0.1 \mathrm{~mm} / \mathrm{s}$ ), blackening ight start in some areas of the film. During irradiation of spots on the stationary film blackening typically does not occur. In other words, there are areas where neither green emission generation nor blackening occurs under the laser radiation of even higher than $33 \mathrm{~kW} / \mathrm{cm}^{2}$ (up to $65 \mathrm{~kW} / \mathrm{cm}^{2}$ ) intensity. These areas are clearly visible in Figure $1 \mathrm{~b}$ as white regions. Therefore, it is much easier to get the film blackened moving it relative to the laser beam (i.e. producing a line) than irradiating the motionless film at a single point. Numerous experiments have shown that a stationary film can also be blackened, depending on the region of the film. However, the probability of finding such a region is quite low. The use of $10 \times$ and $50 \times$ objectives, which provided maximum power densities of 3 and $20 \mathrm{~kW} / \mathrm{cm}^{2}$, respectively, did not lead to blackening, as the power densities were lower than the threshold of laser blackening $\left(33 \mathrm{~kW} / \mathrm{cm}^{2}\right)$. It should also be noted that blackening did not occur on the film with a thickness of $0.5 \mu \mathrm{m}$ at maximum intensity, whether it was moving or stationary. One can see a line, a square, and a triangle "written" on the surface of the $20 \mu \mathrm{m}$ thick film in Figure 6. The optical images in Figure 6 were obtained while using a microscope and a camera incorporated into a Raman spectrometer. It can be seen that the width of the blackened segments in the transverse direction is about $5 \mu \mathrm{m}$, which is slightly larger than the diameter of the laser beam waist $(4.1 \mu \mathrm{m})$. The blackening of the film was shown to be accompanied by green emission by visual observation through a glass filter of the laser irradiated area (Figure 5a). One can see the red spot of the reflected laser in that area when $P=5.4 \mathrm{~kW} / \mathrm{cm}^{2}$ and blackening of the film does not occur, and green emission at $P=65 \mathrm{~kW} / \mathrm{cm}^{2} \mathrm{~m}$ accompanied by the film blackening in Figure $5 \mathrm{c}, \mathrm{d}$. Note that the observed green emission is a one-time event for the irradiated area, i.e. no emission is observed after blackening the film area.

a)

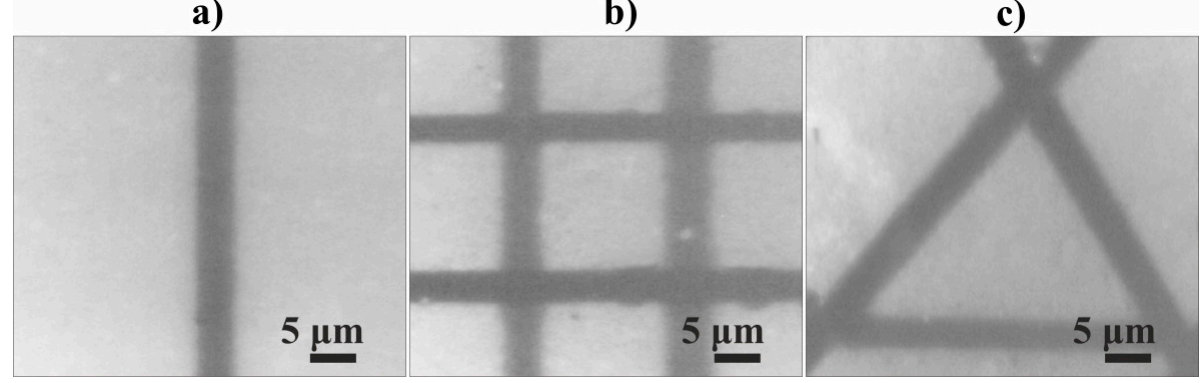

Figure 6. Laser written patterns on the HP-HT nanodiamond film surface: (a) line, (b) square, and (c) triangle under white light illumination.

Figure 7a shows the optical transmittance of the blackened region of the film at a wavelength of $633 \mathrm{~nm}$, depending on its coordinate along the $x$-axis perpendicular to the $y$-axis, which is parallel to the symmetry axis of the blackened line (see Figure 7d). The presented dependence was obtained using a photodetector, the photosensitive part of which with the diameter of $1 \mathrm{~cm}$ was placed in the immediate vicinity of the film while the film and the focused beam move relative to each other $(100 \times)$. The transmittance of the film is shown to be significantly decreased after laser exposure. Figure $7 \mathrm{~b}$ shows the Raman spectra that were obtained for non-blackened and blackened regions of the film at an intensity of $5.4 \mathrm{~kW} / \mathrm{cm}^{2}$ using a $100 \times$ objective. One can see a strong Raman signal with a frequency shift of $1331 \mathrm{~cm}^{-1}$, slightly different from that of a bulk crystalline diamond [32], in the spectrum of a non-blackened region (Figure $7 \mathrm{~b}$, black curve). Note that, depending on the wavelength of the pumping laser and the nanoparticle mean size, the Raman shifts of detonation nanodiamonds, CVD nanodiamonds, and HP-HT nanodiamonds are known to be in the range of 1325-1332 $\mathrm{cm}^{-1}$ [33-38]. In the Raman spectrum of a blackened region, there is no diamond signal (see Figure $7 \mathrm{~b}$, red curve), but 
there are two distinct broad Raman lines with frequency shifts of maximums of 1320 and $1580 \mathrm{~cm}^{-1}$, typical for $\mathrm{sp}^{2}$-carbon. Figure $7 \mathrm{c}$ shows the dependence of Raman peak intensity of the HP-HT nanodiamond on $x$ coordinate. The HP-HT nanodiamond Raman peak intensity is mirror-symmetric about $x=0$ in the first approximation.
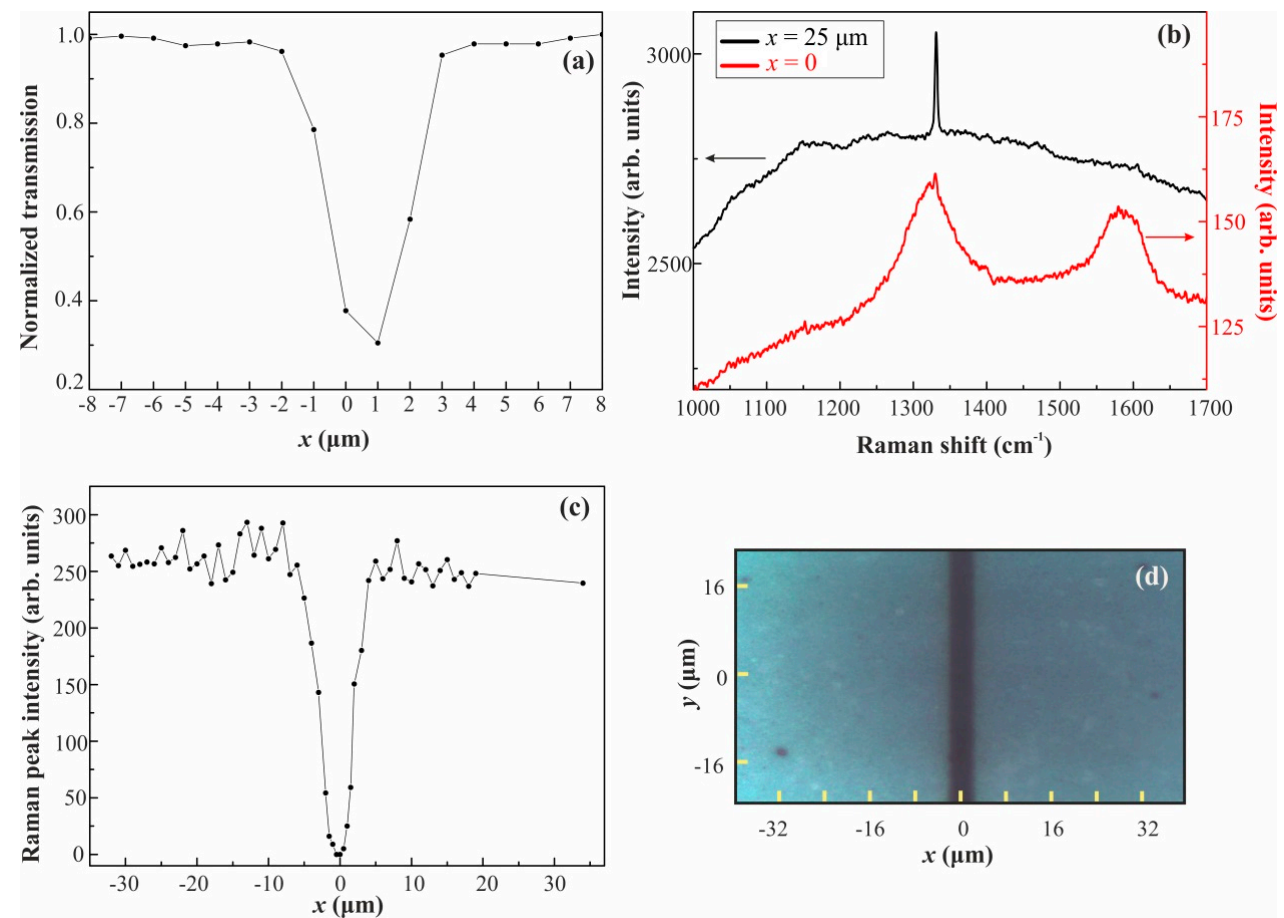

Figure 7. (a) Dependence of differential optical transmittance of the HP-HT nanodiamond film on $x$ coordinate; (b) The Raman spectra of the HP-HT nanodiamond film points located on the $x$-axis perpendicular to the laser- blackened line on the film parallel to the $y$-axis, with $x=25$ (black) and 0 (red) $\mu \mathrm{m}$; (c) the dependence of Raman peak intensity of the HP-HT nanodiamond on $x$ coordinate; and, (d) an optical image of a blackened line perpendicular to the $x$ axis.

Figure 8a shows a three-dimensional (3D) image of a blackened line segment obtained while using the atomic force microscope. It can be seen that the blackened area is a notch, on both sides of which, there are parallel formations in the form of a ridge, raised above the average level of the film surface. The depth of the notch and the height of the shaft are about 150 and $100 \mathrm{~nm}$, respectively (see Figure $8 b$ ).

a)

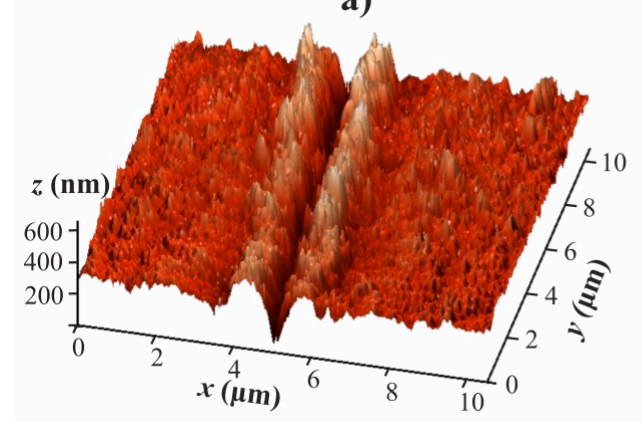

b)

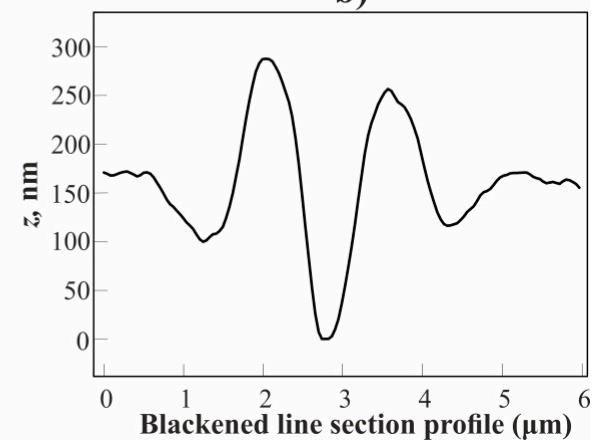

Figure 8. (a) Three-dimensional (3D) image of a blackened line segment obtained using AFM; and, (b) the blackened line section profile. 
Figure 9a shows an image of a blackened line segment obtained while using a scanning electron microscope in the mode of secondary electrons detection. The notch located along the line of laser exposure is clearly visible. Its width in the transverse direction is $3.2 \mu \mathrm{m}$, which roughly coincides with the width of the notch presented in the AFM image (see Figure 8). In addition, it can be seen that the zone of laser irradiation extends in the form of two parallel dark stripes with unmodified surface relief along the notch on both its sides. As a result, the width of the laser irradiation zone along the axis perpendicular to the direction of movement of the focused laser beam reaches $18-20 \mu \mathrm{m}$, which is significantly larger than the laser beam waist diameter. Figure $9 b$ shows the SEM image of the area that is located at the bottom of the laser-induced notch shown in Figure 9a. It can be seen that the granularity of the film surface is noticeably reduced after laser modification.

a)

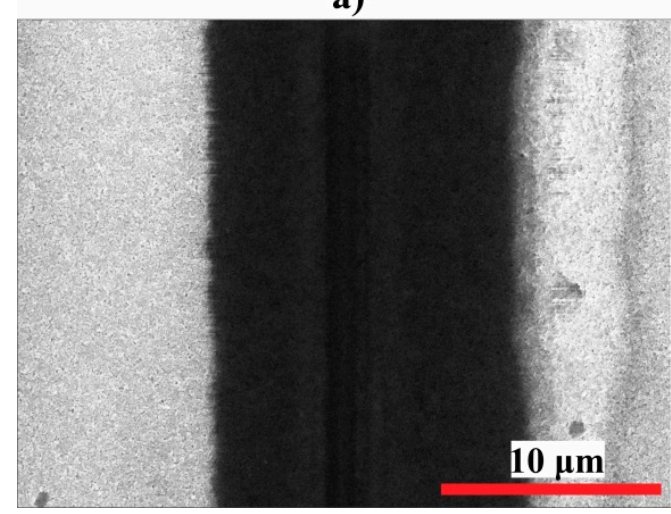

b)

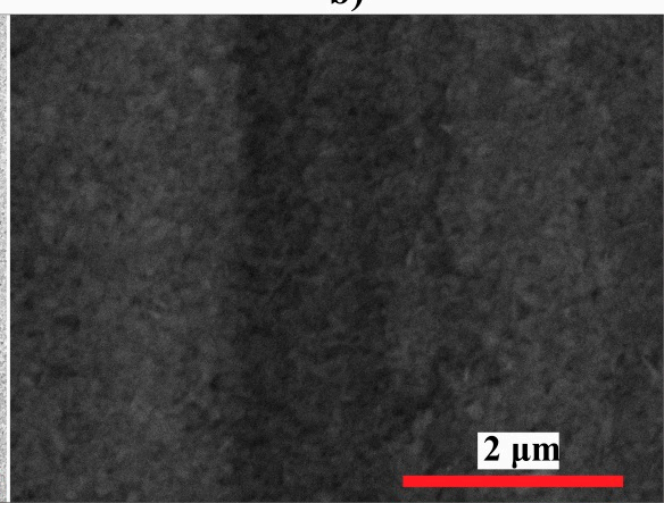

Figure 9. SEM images of (a) the blackened line segment and (b) the bottom of the blackened line segment on the HP-HT ND film.

The experiments have shown that blackening and green emission are unlikely to occur when the film is stationary. In addition to visual observation, this is confirmed by Raman spectra of the same point on a fixed film. Figure 10a shows the Raman spectra of the film recorded at a randomly chosen area, which was irradiated for intervals of time $\Delta t=0.5,10$ and $120 \mathrm{~min}$. by $65 \mathrm{~kW} / \mathrm{cm}^{2}$ laser radiation. The spectra were measured after $\Delta t$ irradiation time at $65 \mathrm{~kW} / \mathrm{cm}^{2}$. It can be seen that the presented spectra have a broad luminescence band in the spectral range of $650-700 \mathrm{~nm}$ and one sharp diamond peak with a frequency shift of about $1331 \mathrm{~cm}^{-1}$. Figure 10b depicts HP-HT nanodiamond Raman peak intensity and its shift in a randomly chosen area of the stationary film as a function of laser exposure time at $65 \mathrm{~kW} / \mathrm{cm}^{2}$. Figure 10c shows fitted HP-HT nanodiamond Raman peaks for the film point irradiated for $\Delta t=0.5$ and $120 \mathrm{~min}$. Figure $10 \mathrm{~b}, \mathrm{c}$ demonstrate that an increase in the duration of laser irradiation $\Delta t$ does not lead to a noticeable change in the Raman intensity and shift of the HP-HT nanodiamond peak. At the same time, the decrease in the luminescence intensity in a wide spectral range is clearly observed, i.e. the longer the film is irradiated, the lower the luminescence intensity at wavelengths in the spectral range of $650-700 \mathrm{~nm}$ (see Figure 10d). It should be emphasized that, during the lengthy experiment, the results of which are shown in Figure 10a, laser-induced blackening of the film did not occur and the green emission was not observed.

Thus, the transformation of HP-HT nanodiamond particles into sp $^{2}$-carbon, which is accompanied by a green emission, can occur in some areas of the film during its movement relative to a laser beam spot with an intensity of more than $33 \mathrm{~kW} / \mathrm{cm}^{2}$. The partial graphitization of HP-HT nanodiamond particles also happens in the area near and several times larger than the beam waist. In addition to the dependence that is shown in Figure 7c, this is indicated by dark parallel bands with a width from edge to edge equal to $18-20 \mu \mathrm{m}$, appearing on the SEM image (see Figure 9). It is obvious that these dark bands in the SEM image arise from the increase of the HP-HT nanodiamond film electrical conductivity due to the formation of $\mathrm{sp}^{2}$-carbon. 

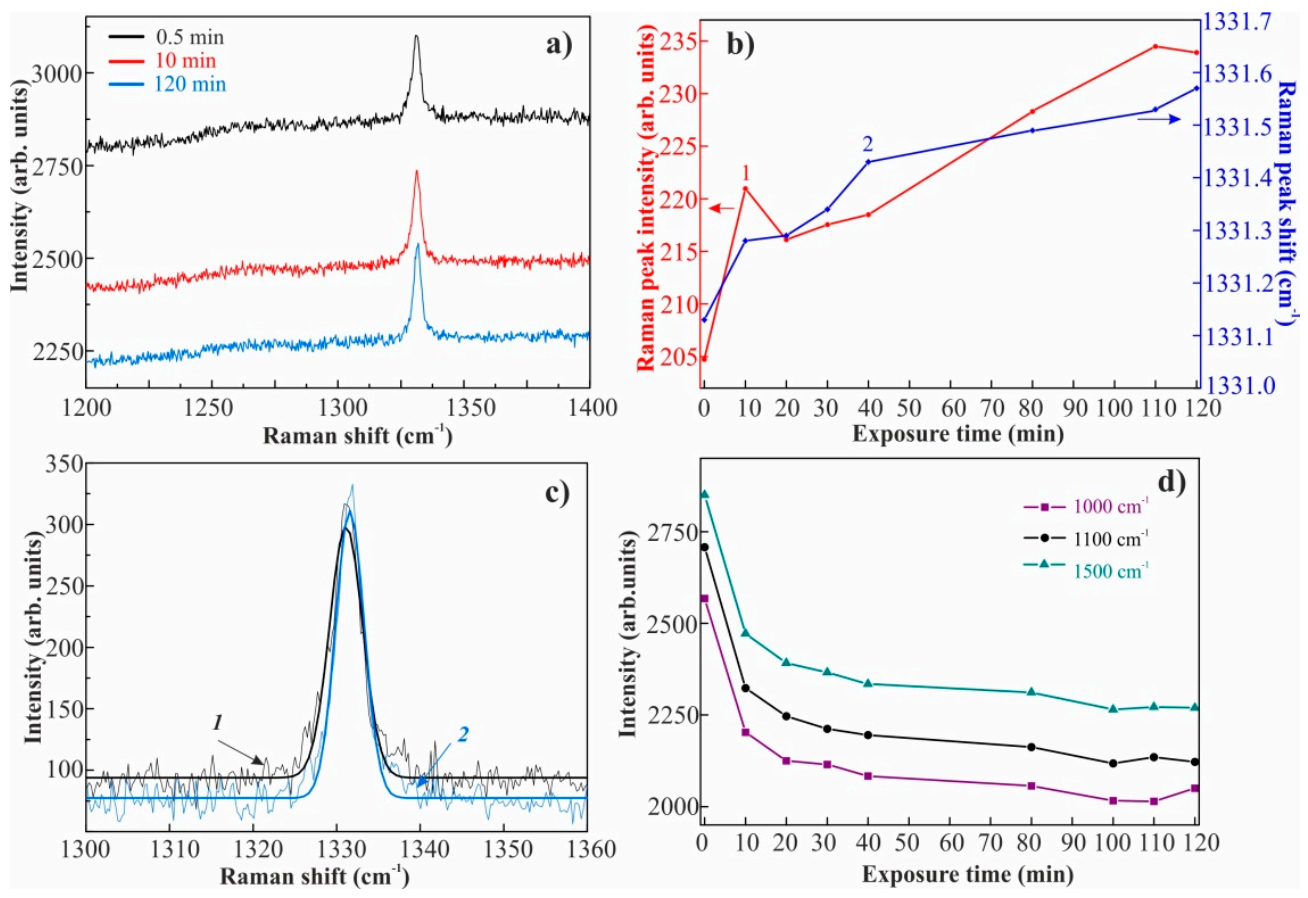

Figure 10. (a) Raman spectra of a randomly chosen place of the stationary HP-HT nanodiamond film irradiated by $65 \mathrm{~kW} / \mathrm{cm}^{2}$ laser radiation for different intervals of time (0.5, 10, and $120 \mathrm{~min}$.); (b) HP-HT nanodiamond Raman peak intensity and its Raman shift of a randomly chosen place of the stationary film as a function of laser exposure time at $65 \mathrm{~kW} / \mathrm{cm}^{2}$; (c) Raman spectra of a randomly chosen place of the stationary HP-HT nanodiamond film irradiated by $65 \mathrm{~kW} / \mathrm{cm}^{2}$ laser radiation for intervals of time (curve 1) $\Delta t=0.5 \mathrm{~min}$. and (curve 2) $\Delta t=120 \mathrm{~min}$. measured at $65 \mathrm{~kW} / \mathrm{cm}^{2}$ excitation intensity after subtraction of baselines with the peaks fitted; (d) luminescence intensity at Stokes Raman frequency shifts of 1000,1100 , and $1500 \mathrm{~cm}^{-1}$ of a randomly chosen place of the stationary HP-HT nanodiamond film irradiated by $65 \mathrm{~kW} / \mathrm{cm}^{2}$ laser radiation as a function of laser exposure time.

\section{Discussion}

The structural transformation of $\mathrm{sp}^{3}$ - to $\mathrm{sp}^{2}$-carbon was previously observed by Osswald et al. [39] while irradiating powders of detonation nanodiamonds [40,41] with a cw $325 \mathrm{~nm}$ helium-cadmium laser $\left(1.3 \mathrm{~kW} / \mathrm{cm}^{2}\right)$. Such transformation occurred because of high-temperature heating of the irradiated region of the sample that was caused by absorption of the incident $U V$ light by the nanodiamond particles and it was accompanied by thermoluminescence in a wide range of wavelengths (325-700 nm) [39].

However, our experimental results cannot be explained by simple heating to the high-temperatures for the following reasons. Firstly, Figure 10a shows that prolonged focused laser irradiation of a motionless film at a maximum intensity of $65 \mathrm{~kW} / \mathrm{cm}^{2}$ does not cause blackening and structural changes. Only the luminescence amplitude decreases in a wide range of wavelengths at the point of laser exposure, as the exposure time increases (Figure 10d). Secondly, laser-induced blackening only happens when the film and the focused beam move relative to each other. Thirdly, the laser modification of the film is accompanied by the green luminescence. Fourth, after laser modification, the absorption coefficient of the film at the wavelength of $633 \mathrm{~nm}$ is several times higher, as can be seen from Figure 7a; however, re-exposure of the same spot of the film at the highest intensity of the laser $\left(65 \mathrm{~kW} / \mathrm{cm}^{2}\right)$ does not lead to any additional green emission or structural changes, i.e. green emission and laser blackening are one-time events. Also note that green emission and laser blackening occurs not only in ambient atmosphere, but also in the Ar atmosphere.

The results that are presented above can be explained on the assumption that the HP-HT nanodiamond films contain impurity centers that are distributed non-uniformly among different diamond particles. The well-studied color centers in diamond are $[\mathrm{N}-\mathrm{V}]-$ centers. The main ${ }^{3} \mathrm{~A}_{2},{ }^{2} \mathrm{E}$, 
and excited ${ }^{3} \mathrm{E},{ }^{2} \mathrm{~A}_{2}$ energy levels of the electronic transitions ${ }^{3} \mathrm{~A}_{2} \rightarrow{ }^{3} \mathrm{E}$ and ${ }^{2} \mathrm{E} \rightarrow{ }^{2} \mathrm{~A}_{2}$ of $[\mathrm{N}-\mathrm{V}]^{-}$-and $[\mathrm{N}-\mathrm{V}]^{0}$-centers, respectively, lie between the valence and the conduction band of diamond [42-44]. Moreover, the zero phonon line related to the ${ }^{3} \mathrm{~A}_{2} \rightarrow{ }^{3} \mathrm{E}$ and ${ }^{2} \mathrm{E} \rightarrow{ }^{2} \mathrm{~A}_{2}$ transitions have the wavelengths of $637 \mathrm{~nm}(1.945 \mathrm{eV})$ and $575 \mathrm{~nm}(2.156 \mathrm{eV})$, respectively [15,45,46]. The ground state ${ }^{3} \mathrm{~A}_{2}$ of the $[\mathrm{N}-\mathrm{V}]^{-}$-center is above the valence band by $2.94 \mathrm{eV}$ (recombination energy) and lower by $2.6 \mathrm{eV}$ (ionization energy) of the conduction band [42]. Upon irradiation of [N-V]--centers at the wavelength of $637 \mathrm{~nm}$, resonance excitation of the upper-level ${ }^{3} \mathrm{~A}_{2} \rightarrow{ }^{3} \mathrm{E}$ with its subsequent ionization is possible, in accordance with Aslam et al. [42]. As a result, an $[\mathrm{N}-\mathrm{V}]^{0}$-center is formed in the excited state ${ }^{2} \mathrm{~A}_{2}$. The transition from excited state ${ }^{2} \mathrm{~A}_{2}$ to the ground state occurs due to the emission of a photon at a wavelength of $575 \mathrm{~nm}$. Thus, by irradiating a [N-V]-center with radiation at $637 \mathrm{~nm}$, it is possible to obtain emission at a shorter wavelength of $575 \mathrm{~nm}$.

In the studied HP-HT nanodiamonds, the $[\mathrm{N}-\mathrm{V}]^{-}$-centers were not specifically created. They are formed only upon irradiation of diamond particles containing substitutional $\mathrm{N}$ with high-energy electrons with subsequent annealing at high temperature $[47,48]$. However, the studied HP-HT nanodiamonds contain Ni- and N- centers $[11,16,19,20,45,49,50]$. From Figure 4 , it can be seen that there are peaks in the luminescence spectrum at the wavelengths of 485 and $528-529 \mathrm{~nm}$. These luminescence peaks are related to the Ni- [16] and [Ni-N]-complexes [19]. It is noteworthy that there are the same peaks in the up-conversion luminescence spectrum obtained at the wavelength of $633 \mathrm{~nm}$ (see Figure 4d). Therefore, the investigated HP-HT nanodiamonds have a system of energy levels that allow the resonant absorption of one or several He-Ne laser photons at $1.96 \mathrm{eV}$. This enables the population of the upper levels of energy transitions of complexes [Ni] and [Ni-N]. If the population of the upper levels occurs then blue-green up-conversion luminescence is observed [51]. Synchronously, the absorption of an additional photon by the impurity centers at these upper-levels with relatively long lifetime might occur. This leads to the transition of the impurity centers to the ionized state, similar to the transition of the [N-V]-centers during laser illumination $[15,42]$. Consequently, free electrons arise in the laser beam spot on the film, beginning to efficiently absorb incident red light at $633 \mathrm{~nm}$. This causes the sharp temperature increase in the laser beam spot, which results in the diamond into $\mathrm{sp}^{2}$-carbon transformation, i.e. blackening. Subsequent laser illumination of the blackened area without the diamond impurity complexes does not lead to resonance photon absorption and, due to the low intensity of the laser used, the film cannot achieve a high enough temperature to emit thermally induced light, as it was described in [39]. It is known that impurities incorporated into diamond lattice during synthesis are non-uniformly distributed within individual particles and among different particles [52]. Therefore, the impurity centers are randomly distributed on the film, which explains the blackening effect that mostly takes place when the laser beam spot is scanning the surface of the film. The motion of the film greatly increases the probability of the intersection of randomly distributed impurity centers with the beam waist of the laser. The number of impurity centers affected by the laser beam in a unit of time also increases. As soon as the laser affects such center, efficient absorption of the laser radiation begins and the diamond to $\mathrm{sp}^{2}$-carbon transformation occurs. The thickness of the film also plays an important role, since a certain amount of impurity centers within the film volume illuminated by the beam along the film depth needs to be activated by the laser beam simultaneously to raise the local temperature to a critical point when the graphitization occurs. As the graphitization starts, it also spreads into the nearby regions (as wide as $10 \mu \mathrm{m}$ across the direction of the beam movement, Figure 9), even though the density of the impurity centers there is low.

There is a recent paper regarding laser-induced broadband light emission and structural changes in HP-HT micro-size diamonds after continuous excitation at near-infrared wavelengths, proposing a model of an $\mathrm{sp}^{2}-\mathrm{sp}^{3}$ hybridization switch process assisting the multiphoton ionization and free to bound recombination of electron between two carbon atoms [53]. These results are in agreement with our hypothesis of laser-induced modification of the impurity complexes [Ni] and $[\mathrm{Ni}-\mathrm{N}]$ containing nanodiamonds presented above. 


\section{Conclusions}

We have demonstrated the possibility of structural modification of $150 \mathrm{~nm}$ HP-HT nanodiamond films while using less than $10 \mathrm{~mW} \mathrm{cw}$ laser radiation at $633 \mathrm{~nm}$. Changes in the film structure are due to diamond to $\mathrm{sp}^{2}$-carbon transformation and they are accompanied by green luminescence. The laser-induced modification of artificial diamond material is explained by a two-step sequential resonance absorption through an intermediate long lifetime state, ionizing the impurity [Ni]and [Ni-N]-centers in the HP-HT nanodiamonds. These findings demonstrate the possibility of laser destruction of luminescent nickel-containing centers in HP-HT nanodiamonds by inducing graphitization of the particles and they may have future application in a laser-assisted extraction of higher purity HP-HT nanodiamonds.

Author Contributions: Conceptualization, K.G.M. and G.M.M.; methodology, K.G.M., T.N.M. and G.M.M.; validation, K.G.M., G.M.M. and O.A.S.; investigation, K.G.M., G.M.M., A.E.F. and T.N.M.; resources, O.A.S. and N.A.N.; writing —original draft preparation, K.G.M. and G.M.M.; writing-review and editing, K.G.M., G.M.M., O.A.S., N.A.N., T.N.M. and A.E.F.; supervision, G.M.M. and O.A.S.; project administration, G.M.M. All authors have read and agreed to the published version of the manuscript.

Funding: This research was funded by the Ministry of Education and Science of the Russian Federation, state registration number AAAA-A19-119021890083-0.

Acknowledgments: This study was performed using equipment of the Shared Use Center "Center of Physical and Physicochemical Methods of Analysis and Study of the Properties and Surface Characteristics of Nanostructures, Materials, and Products" UdmFRC UB RAS.

Conflicts of Interest: The authors declare no conflict of interest.

\section{References}

1. Mochalin, V.N.; Shenderova, O.; Ho, D.; Gogotsi, Y. The properties and applications of nanodiamonds. Nat. Nanotechnol. 2012, 7, 11-23. [CrossRef] [PubMed]

2. Muller, O.; Pichot, V.; Merlat, L.; Spitzer, D. Optical limiting properties of surface functionalized nanodiamonds probed by the Z-scan method. Sci. Rep. 2019, 9, 519. [CrossRef] [PubMed]

3. Shvidchenko, A.V.; Eidelman, E.D.; Vul', A.Y.; Kuznetsov, N.M.; Stolyarova, D.Y.; Belousov, S.I.; Chvalun, S.N. Colloids of detonation nanodiamond particles for advanced applications. Adv. Colloid Interface Sci. 2019, 268, 64-81. [CrossRef] [PubMed]

4. Shumilov, F.A.; Levitskii, V.S. Immobilization of Single Particles of Detonation Nanodiamonds in Langmuir-Blodgett Films Using Octadecylamine. J. Superhard Mater. 2019, 41, 412-420. [CrossRef]

5. Dolmatov, V.Y. Detonation synthesis ultradispersed diamonds: Properties and applications. Russ. Chem. Rev. 2001, 70, 607-626. [CrossRef]

6. Mermoux, M.; Crisci, A.; Petit, T.; Girard, H.A.; Arnault, J.-C. Surface Modifications of Detonation Nanodiamonds Probed by Multiwavelength Raman Spectroscopy. J. Phys. Chem. C 2014, 118, 23415-23425. [CrossRef]

7. Shenderova, O.A.; McGuire, G.E. Science and engineering of nanodiamond particle surfaces for biological applications (Review). Biointerphases 2015, 10, 030802. [CrossRef]

8. Bundy, F.P.; Hall, H.T.; Strong, H.M.; Wentorfjun, R.H. Man-Made Diamonds. Nature 1955, 176, 51-55. [CrossRef]

9. Walker, J. Optical absorption and luminescence in diamond. Rep. Prog. Phys. 1979, 42, 1605-1659. [CrossRef]

10. Gruber, A. Scanning Confocal Optical Microscopy and Magnetic Resonance on Single Defect Centers. Science 1997, 276, 2012-2014. [CrossRef]

11. Collins, A.T. The characterisation of point defects in diamond by luminescence spectroscopy. Diam. Relat. Mater. 1992, 1, 457-469. [CrossRef]

12. Nadolinny, V.A.; Yelisseyev, A.P. New paramagnetic centres containing nickel ions in diamond. Diam. Relat. Mater. 1994, 3, 17-21. [CrossRef]

13. Collins, A.T.; Kanda, H.; Burns, R.C. The segregation of nickel-related optical centres in the octahedral growth sectors of synthetic diamond. Philos. Mag. B 1990, 61, 797-810. [CrossRef] 
14. Jelezko, F.; Tietz, C.; Gruber, A.; Popa, I.; Nizovtsev, A.; Kilin, S.; Wrachtrup, J. Spectroscopy of Single N-V Centers in Diamond. Single Mol. 2001, 2, 255-260. [CrossRef]

15. Manson, N.B.; Harrison, J.P. Photo-ionization of the nitrogen-vacancy center in diamond. Diam. Relat. Mater. 2005, 14, 1705-1710. [CrossRef]

16. Collins, A.T.; Spear, P.M. The $1.40 \mathrm{eV}$ and $2.56 \mathrm{eV}$ centres in synthetic diamond. J. Phys. C Solid State Phys. 1983, 16, 963-973. [CrossRef]

17. Kupriyanov, I.; Gusev, V.; Borzdov, Y.; Kalinin, A.; Pal'yanov, Y. Photoluminescence study of annealed nickeland nitrogen-containing synthetic diamond. Diam. Relat. Mater. 1999, 8, 1301-1309. [CrossRef]

18. Collins, A.T. Spectroscopy of defects and transition metals in diamond. Diam. Relat. Mater. 2000, 9, 417-423. [CrossRef]

19. Yelisseyev, A.; Babich, Y.; Nadolinny, V.; Fisher, D.; Feigelson, B. Spectroscopic study of HPHT synthetic diamonds, as grown at $1500{ }^{\circ} \mathrm{C}$. Diam. Relat. Mater. 2002, 11, 22-37. [CrossRef]

20. Lindblom, J.; Holsa, J.; Papunen, H.; Hakkanen, H. Luminescence study of defects in synthetic as-grown and HPHT diamonds compared to natural diamonds. Am. Mineral. 2005, 90, 428-440. [CrossRef]

21. Rothschild, M.; Arnone, C.; Ehrlich, D.J. Excimer-laser etching of diamond and hard carbon films by direct writing and optical projection. J. Vac. Sci. Technol. B Microelectron. Nanom. Struct. 1986, 4, 310. [CrossRef]

22. Komlenok, M.S.; Kononenko, V.V.; Ralchenko, V.G.; Pimenov, S.M.; Konov, V.I. Laser Induced Nanoablation of Diamond Materials. Phys. Procedia 2011, 12, 37-45. [CrossRef]

23. Mildren, R.P.; Downes, J.E.; Brown, J.D.; Johnston, B.F.; Granados, E.; Spence, D.J.; Lehmann, A.; Weston, L.; Bramble, A. Characteristics of 2-photon ultraviolet laser etching of diamond. Opt. Mater. Express 2011, 1, 576. [CrossRef]

24. Konov, V.I. Laser in micro and nanoprocessing of diamond materials. Laser Photon. Rev. 2012, 6, 739-766. [CrossRef]

25. Komlenok, M.S.; Kononenko, V.V.; Gololobov, V.M.; Konov, V.I. On the role of multiphoton light absorption in pulsed laser nanoablation of diamond. Quantum Electron. 2016, 46, 125-127. [CrossRef]

26. Arutyunyan, N.R.; Komlenok, M.S.; Zavedeev, E.V.; Pimenov, S.M. Raman Spectroscopy of Amorphous Carbon Films Modified by Single-Pulse Irradiation of Nanosecond and Femtosecond Lasers. Phys. Status Solidi 2018, 255, 1700225. [CrossRef]

27. Hora, H.; Miley, G.H.; Eliezer, S.; Nissim, N. Pressure of picosecond CPA laser pulses substitute ultrahigh thermal pressures to ignite fusion. High Energy Density Phys. 2020, 35, 100739. [CrossRef]

28. Steinke, S.; Henig, A.; Schnürer, M.; Sokollik, T.; Nickles, P.V.; Jung, D.; Kiefer, D.; Hörlein, R.; Schreiber, J.; Tajima, T.; et al. Efficient ion acceleration by collective laser-driven electron dynamics with ultra-thin foil targets. Laser Part. Beams 2010, 28, 215-221. [CrossRef]

29. Mikheev, G.M.; Mikheev, K.G.; Mogileva, T.N.; Puzyr, A.P.; Bondar, V.S. Laser image recording on detonation nanodiamond films. Quantum Electron. 2014, 44, 1-3. [CrossRef]

30. Mikheev, K.G.; Mogileva, T.N.; Fateev, A.E.; Nunn, N.; Shenderova, O.A.; Mikheev, G.M. Laser modification of high-pressure high-temperature nanodiamonds. J. Phys. Conf. Ser. 2019, 1410, 012018. [CrossRef]

31. Mikheev, G.M.; Krivenkov, R.Y.; Mogileva, T.N.; Mikheev, K.G.; Nunn, N.; Shenderova, O.A. Saturable Absorption in Suspensions of Single-Digit Detonation Nanodiamonds. J. Phys. Chem. C 2017, 121, 8630-8635. [CrossRef]

32. Solin, S.A.; Ramdas, A.K. Raman Spectrum of Diamond. Phys. Rev. B 1970, 1, 1687-1698. [CrossRef]

33. Mochalin, V.; Osswald, S.; Gogotsi, Y. Contribution of Functional Groups to the Raman Spectrum of Nanodiamond Powders. Chem. Mater. 2009, 21, 273-279. [CrossRef]

34. Chung, P.-H.; Perevedentseva, E.; Cheng, C.-L. The particle size-dependent photoluminescence of nanodiamonds. Surf. Sci. 2007, 601, 3866-3870. [CrossRef]

35. Zolotukhin, A.A.; Ismagilov, R.R.; Dolganov, M.A.; Obraztsov, A.N. Morphology and Raman Spectra Peculiarities of Chemical Vapor Deposition Diamond Films. J. Nanoelectron. Optoelectron. 2012, 7, $22-28$. [CrossRef]

36. Korepanov, V.I.; Hamaguchi, H.; Osawa, E.; Ermolenkov, V.; Lednev, I.K.; Etzold, B.J.M.; Levinson, O.; Zousman, B.; Epperla, C.P.; Chang, H.-C. Carbon structure in nanodiamonds elucidated from Raman spectroscopy. Carbon N. Y. 2017, 121, 322-329. [CrossRef] 
37. Jirásek, V.; Čech, J.; Kozak, H.; Artemenko, A.; Černák, M.; Kromka, A. Plasma treatment of detonation and HPHT nanodiamonds in diffuse coplanar surface barrier discharge in H 2 /N 2 flow. Phys. Status Solidi 2016, 213, 2680-2686. [CrossRef]

38. Stehlik, S.; Varga, M.; Ledinsky, M.; Jirasek, V.; Artemenko, A.; Kozak, H.; Ondic, L.; Skakalova, V.; Argentero, G.; Pennycook, T.; et al. Size and Purity Control of HPHT Nanodiamonds down to $1 \mathrm{~nm}$. J. Phys. Chem. C 2015, 119, 27708-27720. [CrossRef]

39. Osswald, S.; Behler, K.; Gogotsi, Y. Laser-induced light emission from carbon nanoparticles. J. Appl. Phys. 2008, 104, 074308. [CrossRef]

40. Osswald, S.; Yushin, G.; Mochalin, V.; Kucheyev, S.O.; Gogotsi, Y. Control of sp 2/sp 3 Carbon Ratio and Surface Chemistry of Nanodiamond Powders by Selective Oxidation in Air. J. Am. Chem. Soc. 2006, 128, 11635-11642. [CrossRef]

41. Portet, C.; Yushin, G.; Gogotsi, Y. Electrochemical performance of carbon onions, nanodiamonds, carbon black and multiwalled nanotubes in electrical double layer capacitors. Carbon N. Y. 2007, 45, 2511-2518. [CrossRef]

42. Aslam, N.; Waldherr, G.; Neumann, P.; Jelezko, F.; Wrachtrup, J. Photo-induced ionization dynamics of the nitrogen vacancy defect in diamond investigated by single-shot charge state detection. New J. Phys. 2013, 15, 013064. [CrossRef]

43. Bourgeois, E.; Jarmola, A.; Siyushev, P.; Gulka, M.; Hruby, J.; Jelezko, F.; Budker, D.; Nesladek, M. Photoelectric detection of electron spin resonance of nitrogen-vacancy centres in diamond. Nat. Commun. 2015, 6, 8577. [CrossRef] [PubMed]

44. Manson, N.B.; Beha, K.; Batalov, A.; Rogers, L.J.; Doherty, M.W.; Bratschitsch, R.; Leitenstorfer, A. Assignment of the NV0 575-nm zero-phonon line in diamond to a 2E-2A2 transition. Phys. Rev. B 2013, 87, 155209. [CrossRef]

45. Gaebel, T.; Domhan, M.; Wittmann, C.; Popa, I.; Jelezko, F.; Rabeau, J.; Greentree, A.; Prawer, S.; Trajkov, E.; Hemmer, P.R.; et al. Photochromism in single nitrogen-vacancy defect in diamond. Appl. Phys. B 2006, 82, 243-246. [CrossRef]

46. Beha, K.; Batalov, A.; Manson, N.B.; Bratschitsch, R.; Leitenstorfer, A. Optimum Photoluminescence Excitation and Recharging Cycle of Single Nitrogen-Vacancy Centers in Ultrapure Diamond. Phys. Rev. Lett. 2012, 109, 097404. [CrossRef]

47. Davies, G.; Lawson, S.C.; Collins, A.T.; Mainwood, A.; Sharp, S.J. Vacancy-related centers in diamond. Phys. Rev. B 1992, 46, 13157-13170. [CrossRef]

48. Vlasov, I.I.; Shenderova, O.; Turner, S.; Lebedev, O.I.; Basov, A.A.; Sildos, I.; Rähn, M.; Shiryaev, A.A.; Van Tendeloo, G. Nitrogen and Luminescent Nitrogen-Vacancy Defects in Detonation Nanodiamond. Small 2010, 6, 687-694. [CrossRef]

49. Lu, H.-C.; Peng, Y.-C.; Lin, M.-Y.; Chou, S.-L.; Lo, J.-I.; Cheng, B.-M. Analysis of Nickel Defect in Diamond with Photoluminescence upon Excitation near $200 \mathrm{~nm}$. Anal. Chem. 2015, 87, 7340-7344. [CrossRef]

50. Jelezko, F.; Wrachtrup, J. Single defect centres in diamond: A review. Phys. Status Solidi 2006, 203, 3207-3225. [CrossRef]

51. Zhou, J.; Liu, Q.; Feng, W.; Sun, Y.; Li, F. Upconversion Luminescent Materials: Advances and Applications. Chem. Rev. 2015, 115, 395-465. [CrossRef] [PubMed]

52. Shenderova, O.A.; Shames, A.I.; Nunn, N.A.; Torelli, M.D.; Vlasov, I.; Zaitsev, A. Review Article: Synthesis, properties, and applications of fluorescent diamond particles. J. Vac. Sci. Technol. B 2019, 37, 030802. [CrossRef] [PubMed]

53. Olejniczak, A.; Tomala, R.; Cichy, B.; Głuchowski, P.; Jakimów, M.; Zięba, A.; Kẹpiński, L.; Ignatenko, O.; Stręk, W. Laser-driven proliferation of sp2-sp3 changes during anti-Stokes white light emission of $\mu$-diamonds. Carbon N. Y. 2019, 146, 438-446. [CrossRef]

(C) 2020 by the authors. Licensee MDPI, Basel, Switzerland. This article is an open access article distributed under the terms and conditions of the Creative Commons Attribution (CC BY) license (http://creativecommons.org/licenses/by/4.0/). 